\section{Leaf Ethylene Evolution Level Following High-temperature Stress in Common Bean}

\author{
Karl J. Sauter', David W. Davis', Paul H. $\mathbf{L i}^{2}$, and I.S. Wallerstein ${ }^{3}$ \\ Department of Horticultural Science, University of Minnesota, St. Paul, \\ MN 55108
}

\begin{abstract}
Additional index words. Phaseolus,vulgaris, environmental stress, electrolyte conductivity
\end{abstract}

\begin{abstract}
Yield in common bean, Phaseolus vulgaris L., can be significantly reduced by high temperature (I-IT) during bloom. Ethylene production from plant tissue increases as a consequence of various stresses, including heat stress. The inheritance of leaf ethylene evolution rate (EER) of HT-stressed (35/30C day/night) progenies from crosses among bean genotypes previously categorized as HT sensitive or tolerant, based on cell electrolyte leakage, was investigated. Evidence from generation means analysis of $F_{1}, F_{2}$, and backcross progenies shows EER to be genetically controlled, with additive, dominance, and epistatic effects indicated for low EER. The range (0.62 to 2.52 $\mu \mathrm{g}^{-1} \cdot \mathrm{hr}{ }^{-1}$ ) of EER from field-grown lines and cultivars suggests the existence of considerable genetic variability. EER was associated $(r=-0.70)$ with heat tolerance, as estimated by cell electrolyte; leakage.
\end{abstract}

The common bean is not well-adapted to high-temperature (HT) stress (Smith and Pryor, 1962) and is greatly affected at or near bloom, resulting in decreased yield (Dickson and Boettger, 1984). The nature of HT on physiological mechanisms causing yield reduction is not clear. Resistance of beans to temperature-drought stress (estimated by pod production) has been reported to be due to a single dominant gene in one cultivar and to two genes with epistatic action in a second cultivar (Bouwkamp and Summers, 1982). Marsh et al. (1985) measured -HT tolerance by electrolyte conductivity and concluded that additive and dominance gene action accounted for the major genetic differences in two HT-tolerant $\times$ HT-sensitive crosses. It was concluded that epistasis had to be taken into account to explain the genetic differences in a third cross (Marsh et al, 1985). Dickson and Petzoldt (1989) estimated broad-sense heritabilities $(\mathrm{H})$ for yield of seeds and pods under HT conditions. $\mathrm{H}_{\mathrm{b}}$ ranged from $19 \%$ to $79 \%$, and the analysis indicated quantitative inheritance. Good agreement was found between growth chamber and field results.

Our investigation used ethylene evolution rate (EER) under HT stress as an indicator of degree of HT tolerance because earlier research showed a strong negative association between HT-stress EER and plant growth

Received for publation 11 May 1989. Minnesota Agr. Expt Sta. Journal Seriesno. 17,044. This research was supported in part by BARD project US-851-34. The cost of publishing this paper was defrayed in part by the payment of page charges. Under postal regulations, this paper therefore must be hereby marked advertisement solely to indicate this fact.

'Graduate Research Assistant.

${ }^{2}$ Professor.

${ }^{3}$ Scientist, Dept. of Industrial Crops, Volcani Center, P.O.B. 50250, Bet Dagan, Israel.
(Tingey, 1980). Earlier work in our laboratory involved the study of EER from relatively HT-tolerant (PI 271998) ('Garrofon') and HT-sensitive 'Bush Blue Lake 47' (BBL 47) bean cultivars given HT stress at various light intensities, phases of growth, and times in the diurnal cycle. The HT-sensitive cultivar was most affected by HT at night, producing more ethylene during the dark period. PI 271998 and 'BBL 47' were also determined to be HT-tolerant and HT-sensitive, respectively, via electrolyte conductivity (Marsh et al., 1985; Li et al., 1990) and photosynthetic rate measurements (Chaisompongpan et al., 1990).

Pepper (Capsicum frutescens L.) cultivars previously known to be FIT-stress tolerant, as based on flower bud abscission, were found by Wien (1988) to have less bud abscission following the application of ethephon. Wien et al. (1989) concluded that increased ethylene level was the primary cause of pepper flower bud abscission under low light intensities. They suggested that the role of ethylene in their experiments may have been similar to that observed in the dropping of young cotton bolls subjected to low light or high night temperatures (Guinn, 1976). Ethylene may play a similar role in the dropping of flower buds, flowers, and small pods in beans as a response to HT conditions.

The objectives of the present study were to investigate the inheritance of EER in HTstressed common bean progenies from several crosses and to screen additional bean cultivars and breeding lines for EER following HT stress.

Generation means experiment. After two generations of single plant selection for EER reaction to HT stress, PI 271998 and 'BBL $47^{\prime}$ were crossed and $\mathrm{F}_{2}$ and reciprocal $\mathrm{BC}_{1}$ populations were produced in the greenhouse. A generation means analysis of progenies was conducted from growth cham- ber HT tests according to the following protocols. Scarified seeds of the parent and progeny populations (Table 1) were germinated in compartmentalized $(4.5 \mathrm{~cm}$ in diameter, 60-ml cones) flats filled with commercial starter mix. Uniform seedlings were transplanted into 0.15-m-diameter, 1.5liter pots of a 2 soil : 1 peat : 1 sand (by volume) pasteurized medium when the primary leaves had unfolded but not yet expanded and then were grown in a greenhouse at $23 / 18 \mathrm{C}$ day/night. A randomized complete-block design was used, with nine benches as blocks. Each block contained four plants of each parent, two and six of each reciprocal $F_{1}$ and $F_{2}$, respectively, and 12 of each of the two backcrosses. Blocks were separated by a 2-day planting sequence because of limitations in growth chamber space. Thus, each block constituted a separate experiment in the chamber.

At full bloom (two viable pods set on the first raceme to reach anthesis, with several flowers opening on other racemes), $\approx 36$ days after planting, plants were transferred to the growth chamber for HT treatment at 35/30C day/night and a 12-hr photoperiod [600 $\mu \mathrm{mol} \cdot \mathrm{s}^{-1} \cdot \mathrm{m}^{-2}$ photosynthetically active radiation (PAR) from high-intensity discharge lamps]. At $48 \mathrm{hr}$, leaf samples were collected for ethylene measurement. Middle leaflets from the most recently fully expanded leaves were removed, weighed, placed in 32-ml glass vials, and sealed with rubber serum caps. Samples were placed on a laboratory bench for incubation at 21C. After 2 $\mathrm{hr}, \mathrm{l}-\mathrm{ml}$ gas samples were removed from the vials with a gas-tight syringe and analyzed for ethylene on a HP 5880A gas chromatography (GC) equipped with a Poro Pak Q alumina column and flame ionization detector (Hewlett Packard, Palo Alto, Calif.). The samples were passed through the column at an oven temperature of $60 \mathrm{C}$ and a $\mathrm{N}$ carrier gas flow rate of $30 \mathrm{ml} \cdot \mathrm{min}^{-1}$. Data obtained from the GC were used to determine EER (microliters of ethylene/gram per hour).

After $96 \mathrm{hr}$ of HT, the plants were returned to the greenhouse. Pods and seeds were harvested at dry maturity and were placed in a forced-air drying room for 7 days at $37 \mathrm{C}$ before being weighed.

Differences $(P<0.05)$ were detected among progeny means for EER in the generation means analysis (Table 1). Variation was high but could be removed as a block effect in the analysis of variance. EER for the $F_{1}$ of the cross between PI 271998 and 'BBL 47 ' was $15 \%$ below the midparent and closer to the EER of the tolerant parent (PI 271998) than of the sensitive one ('BBL 47') (Table 1). The $\mathrm{F}_{2}$ was closer to the midparent, although variability was high. The two $B C$ means differed from one another $(P \leq$ $0.05)$ when analyzed separately. Backcrossing to PI 271998, the HT-tolerant parent, was more effective for recovery of low EER than was backcrossing to 'BBL 47' for recovery of high EER.

Gene effects (Hayman and Mather, 1955) indicate additive, dominance, and epistatic effects to be important in the inheritance of 
Table 1. Leaf ethylene evolution rate and pod and seed weight for the parents, $\mathrm{BC}_{1} \mathrm{P}_{1}, \mathrm{~F}_{1}, \mathrm{~F}_{2}$, and $\mathrm{BC}_{1} \mathrm{P}_{2}$, and the midparent of the heat-tolerant by heat-sensitive cross PI $271998 \times$ × $B B L 47$ '.

\begin{tabular}{|c|c|c|c|c|c|}
\hline Generation & $\begin{array}{l}\text { No. } \\
\text { plants }\end{array}$ & $\begin{array}{c}\text { Ethylene } \\
\text { evolution rate } \\
\left(\mu \mathrm{l} \cdot \mathrm{g}^{-1} \cdot \mathrm{hr}^{-1}\right)\end{array}$ & $\begin{array}{l}\text { Percent of } \\
\text { controly }^{y}\end{array}$ & $\begin{array}{c}\text { Dry wt of } \\
\text { pods and seeds } \\
\text { (g) }\end{array}$ & $\begin{array}{l}\text { Percent of } \\
\text { control }\end{array}$ \\
\hline P1 (PI 271998) & 36 & $1.13 \pm 0.93 \mathrm{~b}$ & 96 & $22.1 \pm 5.4$ & 88 \\
\hline $\mathrm{BC}_{1} \mathrm{P}_{1}$ & 108 & $1.14 \pm 0.77 \mathrm{~b}$ & 102 & $23.1 \pm 5.4$ & 85 \\
\hline$F_{1}$ & 36 & $1.24 \pm 1.08 \mathrm{~b}$ & 79 & $22.2 \pm 5.0$ & 97 \\
\hline Midparent ${ }^{\mathbf{x}}$ & 108 & $\begin{array}{l}1.46 \\
150+157 a b\end{array}$ & 109 & $206+58$ & 88 \\
\hline $\begin{array}{l}\mathrm{F}_{2} \\
\mathrm{BC}_{1} \mathrm{P}_{2}\end{array}$ & $\begin{array}{l}100 \\
108\end{array}$ & $\begin{array}{l}1.50 \pm 1.5 / \mathrm{ab} \\
1.50 \pm 1.05 \mathrm{ab}\end{array}$ & $\begin{array}{l}109 \\
117\end{array}$ & $\begin{array}{l}20.6 \pm 5.8 \\
19.7 \pm 5.1\end{array}$ & $\begin{array}{l}88 \\
78\end{array}$ \\
\hline P2 (BBL 47) & 36 & $1.78 \pm 1.39 \mathrm{a}$ & 148 & $17.8 \pm 5.0$ & 78 \\
\hline
\end{tabular}

${ }^{\text {xMean }} \pm \mathrm{SD}$; mean separation by Duncan's new multiple range test, $P=0.05$.

${ }^{y}$ Controls consisted of eight to 14 non-HT-stressed plants for each generation.

${ }^{x}$ Midparent $=(\mathrm{P} 1+\mathrm{P} 2) / 2$.

Table 2. Estimates of genic effects, variance components, and broad-sense heritability for the generation means analysis of the cross PI 271998 $x$ 'BBL 47 '.

\begin{tabular}{|c|c|c|c|}
\hline Genic effects ${ }^{z, y}$ & Variance & mponents ${ }^{2}$ & $\mathrm{H}_{\mathrm{b}}{ }^{2}$ \\
\hline $\begin{array}{ll}\mathrm{m}>1.50 \\
\mathrm{~d} & -0.36 \\
\mathrm{~h} & -0.94 \\
\mathrm{i} & -0.72 \\
\mathrm{j} & -0.04 \\
\mathrm{l} & 0.83\end{array}$ & $\begin{array}{l}\sigma_{\mathrm{E}}^{2} \\
\sigma_{\mathrm{G}}{ }^{2} \\
\sigma_{\mathrm{A}}{ }^{2} \\
\sigma_{\mathrm{D}}{ }^{2}\end{array}$ & $\begin{array}{r}1.32 \\
1.13 \\
3.20 \\
-2.07\end{array}$ & 0.46 \\
\hline
\end{tabular}

${ }^{2}$ All estimates smaller than their standard error. "Hayman and Mather (1955) designations.

Table 3. Leaf ethylene evolution rate for the parents, progenies, and midparent of three tolerant by tolerant crosses involving PI 271998 crossed with 'Hebei No. 1', 'BTS 3', and 'Upland'.

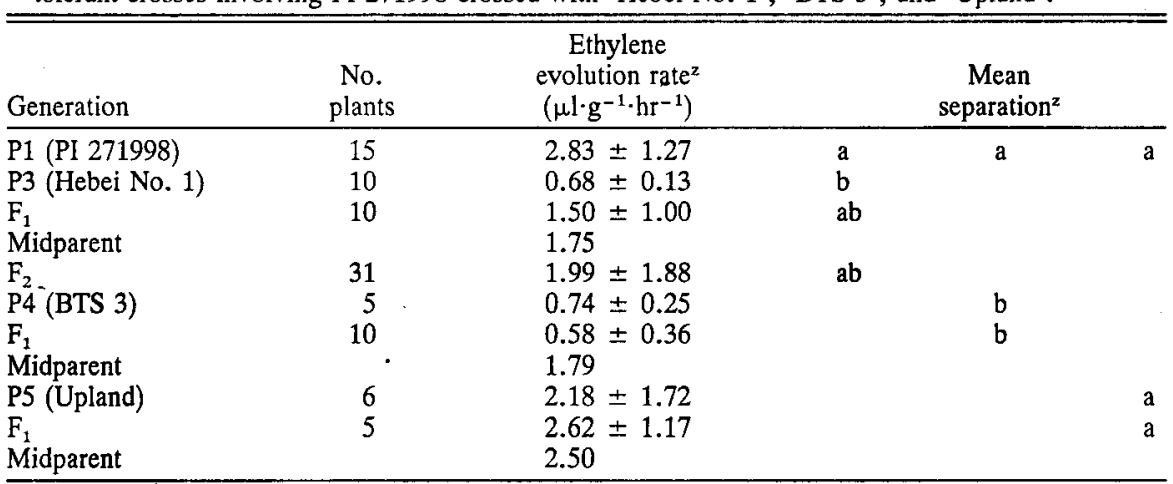

"Mean \pm SD.

yMean separation by Duncan's new multiple range test, $P=0.05$ conducted separately for each cross.

Table 4. A comparison of leaf ethylene evolution rate for field-grown bean cultivars and breeding lines, and their heat acclimation potential as determined by heat killing time from electrolyte leakage via a conductivity test applied to leaflet tissue from greenhouse-grown plants.

\begin{tabular}{lcc}
\hline \hline Entry & $\begin{array}{c}\text { Ethylene } \\
\text { evolution rate } \\
\left(\mu \mathrm{I} \cdot \mathrm{g}^{-1} \cdot \mathrm{hr}^{-1}\right)\end{array}$ & $\begin{array}{c}\text { Heat killing } \\
\text { timex } \\
(\mathrm{min})\end{array}$ \\
\hline BBL 47 & $2.52 \pm 1.61 \mathrm{a}$ & 60 \\
UI 111 & $2.45 \pm 1.19 \mathrm{a}$ & 50 \\
Strike & $1.71 \pm 0.48 \mathrm{ab}$ & 95 \\
Labrador & $1.59 \pm 0.46 \mathrm{ab}$ & 97 \\
Red Cloud & $1.48 \pm 0.40 \mathrm{ab}$ & -- \\
GNUI 59 & $1.39 \pm 0.65 \mathrm{ab}$ & 110 \\
PI 271998 & $1.37 \pm 0.38 \mathrm{ab}$ & 94 \\
P. acutifolius & $1.09 \pm 0.54 \mathrm{~b}$ & - \\
Hebei No. 1 & $1.08 \pm 0.45 \mathrm{~b}$ & 80 \\
G 4727 (Ancash 66) & $0.96 \pm 0.47 \mathrm{~b}$ & 100 \\
85-CT-4986-3 & $0.62 \pm 0.29 \mathrm{~b}$ & 90 \\
\hline
\end{tabular}

${ }^{2}$ Each value is the mean of 10 observations (plants).

'Mean $\pm \mathrm{SD}$; mean separation by Duncan's new multiple range test, $P=0.05$.

'Adapted from Li et al. (1990). Heat killing time is the time in minutes to $50 \%$ electrolyte leakage, as determined by electrolyte conductivity. Correlation $(r)$ for ethylene vs. heat killing time is $-0.7(0 \mathrm{c}$ $=0.95)$.
EER in this cross. Variance components were 2). The genie effects and a unimodal segpeneraimportant in this system, but variation was too great to permit precise interpretation of eritance. The high environmental effect. vironmental variance, as opposed to the genetic variance. The estimated broad-sense heritability $\left(\mathrm{H}_{b}\right)$ of 0.46 for EER in the presence of the additive effects suggests that seevaluate pod and seed set shortly after HT treatment as a way of estimating a temporary HT effect. The "split-set" phenomenon frequently seen as an immediate response to HT stress in the field may represent only a temporary loss of biological yield, but the economic impact in once-over harvesting of snap beans can be severe.

Tolerant by tolerant crosses. PI 271998 was crossed with three other cultivars ('Hebei No. 1', BTS 3, and 'Upland') identified as heat tolerant, relative to 'BBL 47 ', as determined by their electrolyte leakage response to HT stress in our laboratory. These three were screened more recently in our testing program than PI 271998 and 'BBL $47^{\prime}$ and were concluded to be more tolerant than PI 271998.

From the $\mathrm{F}_{1}$ of the cross between PI 271998 and 'Hebei No. 1', an $F_{2}$ was generated in the greenhouse. Parents, reciprocal $\mathrm{F}_{\mathrm{s}} \mathrm{s}$, and the single $\mathrm{F}_{2}$ were evaluated for EER following HT stress in the growth chamber by the same procedure as used for the parents and progenies for the generation means analysis.

Except for the cross between PI 271998 and Upland, the two parents in each combination differed $(P<0.05)$ in EER, with the $\mathrm{F}_{\mathrm{S}}$ tending to fall below the midparent in one cross and below the lower parent in another (Table 3). The mean (1.99) of the single $F_{2}$ population fell closer to the less tolerant of the two parents. Results from these crosses demonstrate the degree of variability that can be found in the determination of EER. While they could be interpreted as supportive of the generation means analysis, they should instead serve to urge a cautious approach in interpretation. The EER for PI 
271998 (2.83) was considerably higher than in the generation means experiment (1.13), due probably to growing season differences. The plant material for the generation means analysis was planted in October, while for the analysis of tolerant by tolerant crosses, the plants were started in June. Fall- and winter-grown bean plants typically have had a lower EER in our laboratory.

Evaluation of field-grown germplasm. Additional germplasm was screened for EER. Ten $P$. vulgaris genotypes ['BBL 47', 'UI 111', PI 271998; 'Strike', 'Labrador', 'Red Kidney', 'GNUI 59', 'Hebei No. 1', G 4727 (Ancash 66], USDA 85-CT-4986-3] and a $\boldsymbol{P}$. acutifolius (tepary bean) entry were fieldgrown $80 \mathrm{~km}$ from the laboratory on an irrigated Hubbard series soil (sandy, mixed Udorthentic Haploborolls) under standard cultural practice. 'BBL 47' and 'UI 111' (a 'Pinto' type) had been identified in earlier work as HT sensitive via conductivity, while all others had been identified as HT tolerant (unpublished data). Plants were spaced 0.1 $\mathrm{m}$ apart in $1.5-\mathrm{m}$-long unreplicated, singlerow plots with $0.75 \mathrm{~m}$ between rows. Plants were evaluated the morning following a 33/ 27C day/night, which had been preceded by several diurnal cycles of cooler temperatures (30/25C day/night). In a protocol similar to that of the first experiment, leaf samples were collected for EER determination and prepared for incubation before transit to the laboratory. The transit time constituted their 2$\mathrm{hr}$ incubation. Ten samples, each from a single plant, were taken from each plot. Although the bean genotypes were not replicated in the field planting, the samples were regarded as replications due to the small area of field and uniform environment involved.

A 4-fold range in mean EER ( 0.62 to 2.52 $\mu$. $\left.1 \cdot \mathrm{g}^{-1} \cdot \mathrm{hr}^{-1}\right)$ was found among the field-grown entries, and for most of the entries, the standard deviation was less than one-half of the mean (Table 4). The two previously identified HT-sensitive entries, 'BBL 47' and 'UI 111 ', showed the greatest EER among the 11 entries. Four of nine HT-tolerant entries, as determined by conductivity, had considerably lower EER than 'BBL 47' or 'UI 111', further suggesting that a relationship may exist between EER and heat tolerance. Results for nine of the 11 entries were compared to data obtained by Li et al. (1990) via electrolyte conductivity (Table 4). Both methods identified the HT-sensitive material and are correlated, having a Pearson correlation coefficient of $-0.70(P \geq 0.05)$. A weaker relationship was observed for comparisons within the HT-tolerant entries.

These results suggest that substantial variation exists for EER and that lower EER should be transferable from a donor parent by backcrossing. Evidence in the literature for association between higher EER and flower and flower bud abscission in response to heat stress is increasing. The screening of plants at an early vegetative stage for EER as a response to heat stress could be useful in breeding programs.

\section{Literature Cited}

Bouwkamp, J.C. and W.L Summers. 1982. Inheritance of resistance of temperature-drought stress in the snap bean. J. Hered. 73:385-386.

Chaisompongpan, N., P.H. Li, D.W. Davis, and A.H. Markhart, III. 1990. Photosynthesis responses to heat stress in Phaseolus vulgaris cultivars differing in heat acclimation potential. Crop Sci. 30:100-104.

Dickson, M.H. and M.A. Boettger. 1984. Effect of high and low temperatures on pollen germination and seed set in snap beans. J. Amer. Soc. Hort. Sci. 109:372-374.

Dickson; M.H. and R. Petzoldt. 1989. Heat tolerance and pod set in green beans. J. Amer. Soc. Hort. Sci. 114:833-836.

Guinn, G. 1976. Nutritional stress and ethylene evolution by young cotton bolls. Crop Sci. 16:89-91.

Hayman, B.J. and K. Mather. 1955. The description of genie interactions in continuous variation. Biometrics 11:69-82.

Li, P. H., D.W. Davis, and Z.Y. Shen. 1990. Ac- climation potential of the common bean to high temperature: Can it be used as a selection criterion for improving crop performance in high temperature environments. Field Crops. (In press.)

Marsh, L. E., D.W. Davis, and P.H. Li. 1985. Selection and inheritance of heat tolerance in the common bean by use of conductivity. J. Amer. Soc. Hort. Sci. 110:680-683.

Smith, F.L. and R.H. Pryor. 1962. Effects of maximum temperature and age on flowering and seed production in three bean varieties. Hilgardia 33:669-688.

Tingey, D.T. 1980. Stress ethylene productionA measure of plant response to stress. HortScience 15:630-633.

Wien, H.C. 1988. Screening techniques for stressinduced flower bud abscission in bell peppers. ASHS/CSHS 1988 Annu. Mtg., East Lansing, Mich., Prog. \& Abstr. HortScience 23(3):800[584].

Wien, H. C., A.D. Turner, and S.F. Yang. 1989. Hormonal basis for low light intensity-reduced flower bud abscission of pepper. J. Amer. Soc. Hort. Sci. 114:981-985. 